\title{
Peningkatan Produksi Desain Pola Pada Industri Rumah Tangga Sepatu Wanita Merk "Vario" Krian
}

\author{
Aris Sudaryanto ${ }^{1 *}$, IGN Anon Maruta ${ }^{2}$ \\ ${ }^{1}$ Fakultas Teknik, Universitas 17 Agustus 1945 Surabaya, ${ }^{2}$ Fakultas Ilmu Sosial dan Ilmu Politik, \\ Universitas 17 Agustus 1945 Surabaya \\ Email : aris@untag-sby.ac.id ${ }^{1}$, anomaruta@untag-sby.ac.id ${ }^{2}$ \\ * Penulis Korespondensi: E-mail: aris@untag-sby.ac.id
}

\begin{abstract}
Micro, Small and Medium Enterprises (MSMEs) have a very vital role to the Indonesian economy. MSMEs are the driving force of a resilient economy facing the onss of economic crisis. During the economic crisis of 1997 - 1998 many major industries rolled out, but MSMEs were able to survive. In 1997 - 1998, Indonesian MSMEs were able to absorb up to $87.62 \%$ of the workforce in Indonesia, or about 57.4 million people. (Data of Indonesian Central Statistics Agency 2017). One of the cities that has many MSMEs is Sidoarjo which is as many as 306,481. One of the MSME centers in Sidoarjo is in Junwangi Krian area which is a shoe MSME center. In Junwangi there are quite a lot of home shoe craftsmen (MSMEs), but many also have difficulty especially in the production process. Difficulty in production among others is the difficulty in making shoe design drawings, so the design process runs slowly. One of the MSMEs who also experienced the problem was Mr. Abdul Majid Rosidi, owner of MSME women's shoes brand "VARIO". Like most shoe craftsmen in Junwangi, Mr. Abdul Majid Rosidi still has difficulty in drawing shoe designs. Starting from the problem, we took the initiative to conduct a Community Service program (PKM) in the form of The Development of Women's Shoe Industry Brand "VARIO" Krian, this. Activities that have been designed and implemented can reflect the spirit of partner MSMEs to continue to innovate to grow their business. This is evident from the enthusiasm of msme partners in each program implementation, as well as the ability to receive, manage, maintain, and develop continuously the programs and infrastructure that have been given.
\end{abstract}

Keywords: UMKM, Shoe Design, picture table.

\begin{abstract}
Abstrak
Usaha Mikro, Kecil dan Menengah (UMKM) mempunyai peran yang sangat vital pada perekonomian Indonesia. UMKM adalah tenaga penggerak perekonomian yang tangguh menghadapi serangan krisis ekonomi. Pada krisis ekonomi tahun 1997 - 1998 banyak industri besar gulung tikar, namun UMKM justru mampu bertahan. Pada tahun 1997 - 1998, UMKM Indonesia mampu menyerap hingga 87,62\% tenaga kerja di Indonesia, atau sekitar 57,4 juta jiwa. (Data Badan Pusat Statistik Indonesia 2017). Salah satu kota yang memiliki banyak UMKM adalah Sidoarjo yaitu sebanyak 306.481. Salah satu pusat UMKM di Sidoarjo adalah di daerah Junwangi Krian yang merupakan sentra UMKM sepatu. Di Junwangi terdapat cukup banyak pengrajin sepatu rumahan (UMKM), namun banyak pula yang mengalami kesulitan terutama dalam proses produksi. Kesulitan dalam produksi antara lain adalah kesulitan dalam membuat gambar desain sepatu, sehingga proses desain berjalan dengan lambat. Salah satu pelaku UMKM yang juga mengalami permasalahan tersebut adalah Bapak Abdul Majid Rosidi, pemilik UMKM sepatu wanita merk "VARIO". Sama seperti sebagian besar pengrajin sepatu di Junwangi, Bapak Abdul Majid Rosidi masih kesulitan dalam membuat gambar desain sepatu. Berangkat dari permasalahan tersebut, maka kami berinisiatif untuk melakukan program Pengabdian Kepada Masyarakat (PKM) berupa Pengembangan Industri Rumah Tangga Sepatu Wanita Merk "VARIO" Krian, ini. Kegiatan yang telah dirancang dan diimplementasikan dapat memantik semangat UMKM mitra untuk terus berinovasi mengembangkan usahanya. Hal tersebut terlihat dari antusiasme UMKM mitra yang tinggi dalam setiap pelaksanaan program, serta
\end{abstract}


kesanggupan untuk menerima, mengelola, merawat, serta mengembangkan terus program serta infrastruktur yang telah dihibahkan.

Kata kunci: UMKM, Desain Sepatu, Meja Gambar

\section{PENDAHULUAN}

\section{Latar Belakang}

Usaha Mikro Kecil Menengah (UMKM) merupakan salah satu hal yang memiliki peran sangat vital dalam perekonomian Indonesia. Peranan tersebut terdiri dari dua hal, yaitu sebagai penggerak perekonomian serta sebagai penyangga stabilitas perekonomian. Peranan UMKM dalam menggerakkan perekonomian Indonesia terbukti dengan banyaknya lapangan pekerjaan yang dapat disediakan oleh UMKM. Pada tahun 1997, ketika krisis ekonomi melanda Indonesia, UMKM masih menjadi sektor tertinggi yang mampu menyerap tenaga kerja sebanyak 57,4 juta jiwa (atau sekitar 87\%). Kenyataan tersebut menjadikan UMKM sebagai sektor industri yang terbukti mampu menggerakkan serta menjaga stabilitas ekonomi Indoneisa.

Dalam perjalanannya UMKM juga telah terbukti menjadi sektor yang mampu merespon, beradaptasi serta fleksibel dalam menghadapi segala dinamika perekonomian yang terjadi di Indonesa. Denga semangat nasionalisme yang tinggi, serta dengan profesionalisme, mengakibatkan UMKM hingga saat ini masih dapat bertahan bahkan berkembang lebih baik. Di Jawa Timur, salah satu kota yang memiliki banyak UMKM adalah Sidoarjo. Kota Sidoarjo menempati urutan ketiga jumlah UMKM terbesar setelah Surabaya dan Gresik. Surabaya memiliki 466.779 UMKM, sedangkan Sidoarjo memiliki UMKM sebanyak 306.481.

Salah satu pusat UMKM di Sidoarjo adalah di daerah Junwangi Krian. Daerah Junwangi ini merupakan sentra UMKM sepatu, dimana di Junwangi terdapat cukup banyak warga yang berprofesi sebagai pengrajin sepatu rumahan (UMKM). Akan tetapi, sejumlah pengrajin sepatu rumahan tersebut masih mengalami berbagai kesulitan, terutama dalam proses produksi. Kesulitan yang dialami dalam proses produksi antara lain adalah kesulitan dalam membuat gambar desain sepatu, sehingga proses desain berjalan dengan lambat. Salah satu pelaku UMKM yang juga mengalami permasalahan tersebut adalah Bapak Abdul Majid Rosidi, pemilik UMKM sepatu wanita merk "VARIO". Sama seperti sebagian besar pengrajin sepatu di Junwangi, Bapak Abdul Majid Rosidi masih kesulitan dalam membuat gambar desain sepatu. Berangkat dari permasalahan tersebut, maka kami berinisiatif untuk melakukan program Pengabdian Kepada Masyarakat (PKM) berupa Pengembangan Industri Rumah Tangga Sepatu Wanita Merk "VARIO" Krian, ini. Manfaat yang diharapkan dari program pengabdian ini ada adalah peningkatan kapasitas produksi UMKM. Manfaat tersebut akan menuju satu muara, yaitu peningkatan omset UMKM.

\section{Tujuan}

Mengingat bahwa permasalahan yang paling mendesak bagi mitra kami saat ini adalah dalam hal proses produksi, lebih tepatnya dalam pembuatan pola desain, maka peningkatan produksi desain pola pada industry rumah tangga sepatu wanita merek "Vario" di Junwangi Krian Sidoarjo ini menjadi sangat penting. 


\section{METODE PELAKSANAAN}

Sebagaimana uraian yang ditulis pada latar belakang masalah, situasi masalah yang dihadapi oleh mitra UMKM adalah pada proses produksi, terutama pada pembuatan pola desain sepatu. Maka metode yang digunakan oleh penulis untuk mengatasi permasalahan tersebut adalah :

1. Pemberian meja gambar pada mitra. Dengan pemberian meja gambar kepada mitra, diharapkan dapat meningkatkan kapasitas serta kualitas pola desain yang dihasilkan dari sisi infrastruktur.

2. Pelatihan pembuatan pola desain menggunakan meja gambar. Adanya infrastruktur, rasanya kurang bermanfaat jika tidak disertai dengan kemampuan dalam penggunaan. Maka dari itu penulis berinisiatif untuk memberikan pelatihan pembuatan pola desain menggunakan meja gambar. Pelatihan ini nantinya akan memperhatikan kapasitas serta kualitas pola yang dihasilkan, serta aspek K3.

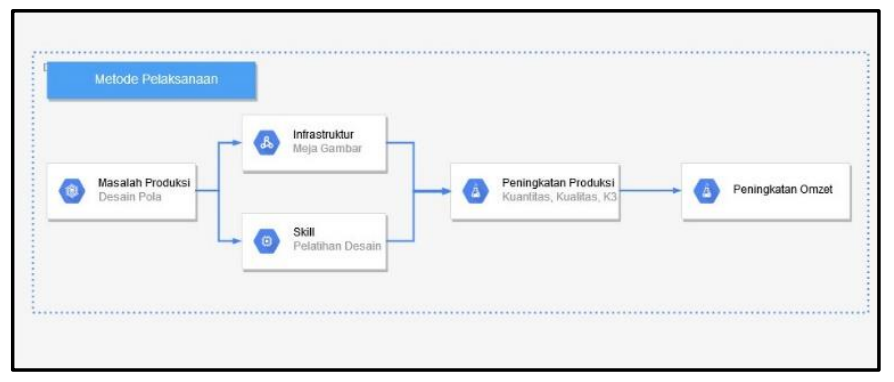

Gambar 1. Metode Pelaksanaan Pengabdian

\section{HASIL dan PEMBAHASAN}

Secara umum, solusi yang ditawarkan dalam permasalahan produksi desain pola sepatu pada UMKM sepatu wanita merk "Vario" Junwangi Krian Sidoarjo ini terdiri dari dua hal. Solusi pertama adalah solusi dari segi infrastruktur. Solusi kedua adalah dari segi skill atau kemampuan. Kedua solusi tersebut dipilih karena rasanya hampir tidak mungkin memaksimalkan proses produksi pada UMKM sepatu wanita merk "Vario" Junwangi Krian Sidoarjo ini tanpa mengakomodir dua hal tersebut, yaitu infrastruktur dan skill / kemampuan.

Andaipun dua solusi tersebut dijalankan salah satunya saja, tentu hasilnya juga tidak akan maksimal. Baiknya infrastruktu jika tidak didukung dengan kemampuan pengguna, rasanya akan kurang berhasil baik. Begitu pula jika kemampuan pengguna baik, namun tidak didukung dengan infrastruktur yang baik juga tidak akan memberikan hasil yang maksimal. Maka dari itu peneliti memberikan solusi baik dari segi infrastruktur maupun kemampuan. Solusi pertama terkait infrastruktur dilakukan dengan cara menghibahkan infrastruktur berupa meja gambar bagi UMKM mitra. Meja gambar yang dihibahkan dibuat dari bahan bahan yang baik, yaitu berupa kayu jati dengan dilapisi plitur. Bahan baku meja gambar yang berasal dari kayu jati ini dapat menjadi jaminan kualitas meja gambar yang dihibahkan. Dimensi meja gambar yang dibuat adalah tinggi $80 \mathrm{~cm}$, lebar $80 \mathrm{~cm}$, serta panjang $125 \mathrm{~cm}$. 


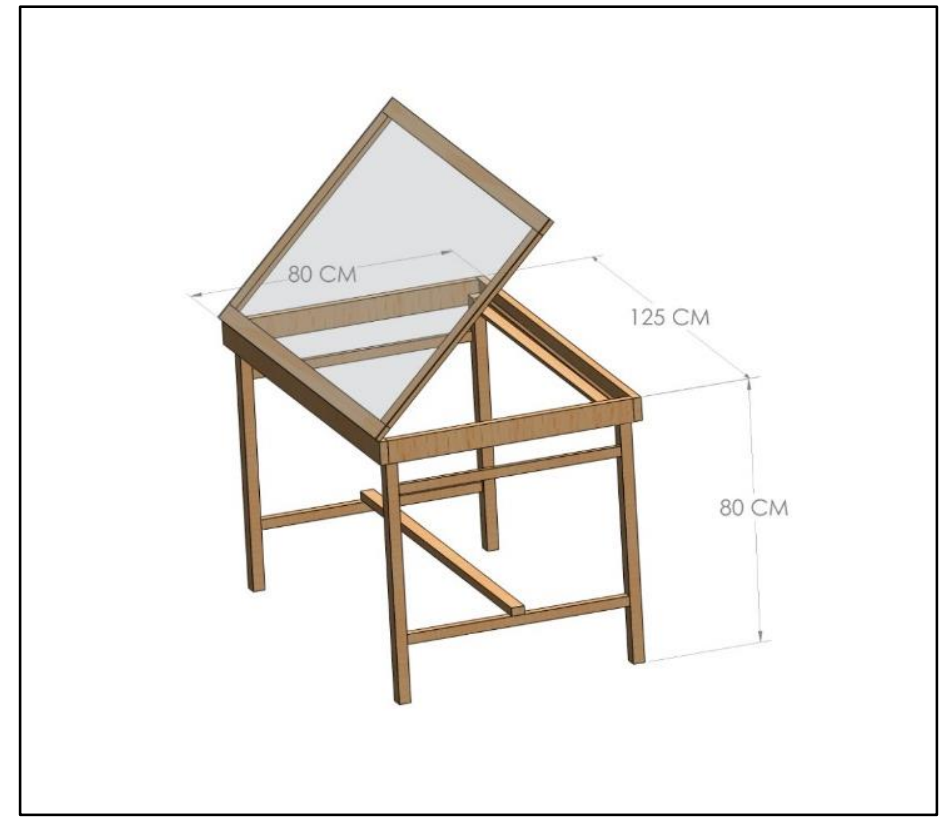

Gambar 2 Desain dan Dimensi Meja Gambar

Untuk memaksimalkan dampak dari penghibahan meja gambar tersebut, maka diperlukan juga pelatihan kepada UMKM mitra agar mampu menggunakan dengan baik. Dengan dilakukannya pelatihan diharapkan dapat meningkatkan kemampuan UMKM mitra, sehingga muara akhirnya adalah peningkatan produktivitas dan omzet. Hasil yang dicapai dari hibah ini adalah :

1. Terpasangnya satu (1) unit meja gambar

2. Penyuluhan pengoperasian dan perawatan alat

3. Penyuluhan tentang pembuatan desain pola sepatu

4. Artikel ilmiah (Prosiding Seminar)

5. Artikel ilmiah pada jurnal ilmiah

\section{KESIMPULAN}

Metode yang telah dirancang dan diimplementasikan telah dapat memantik semangat UMKM mitra untuk terus berinovasi mengembangkan usahanya. Hal tersebut terlihat dari antusiasme UMKM mitra yang tinggi dalam setiap pelaksanaan program. UMKM mitra juga menyanggupi untuk menerima, mengelola, merawat, serta mengembangkan terus program serta infrastruktur yang telah dihibahkan.

\section{DAFTAR PUSTAKA}

LPPI, Bank Indonesia,2015, "Profil Bisnis, Usaha Mikro, Kecil Dan Menengah (UMKM)", Jakarta. Darius Shyafari, Ayu Puspa Anggraini, 2017, "REDESAIN MEJA GAMBAR ANIMASI UNTUK PELAJAR JURUSAN MULTIMEDIA DI SMKN 2 TENGGARONG”, Jurnal Kreatif Vol. 4, No. 2, Jakarta.

Desika Karinayah S, 1991, "Pemberdayaan Usaha Mikro Kecil Dan Menengah di Kabupaten Sidoarjo”, Jurnal Administrasi Negara Universitas Airlangga, Surabaya. 
Jimmy Linggarjati, Arif Aldiansyah, Daniel Sutanto, Otto Hidayat Imanullah, 2009, "PERANCANGAN DAN IMPLEMENTASI SISTEM MEJA GAMBAR DENGAN METODE XYTABLE 2 SUMBU MENGGUNAKAN MOTOR STEPPER DAN EMC (ENHANCED MACHINE CONTROL)", Jurnal Teknik Komputer Vol. 17 No. 2, Jakarta.

Pile, John. F, 1995 “Interior Design”, Hary N Abrams, Inc., Publishers, New York.

CHERRY DHARMAWAN, M.SN, 2011 "KRITERIA DESAIN FASILITAS KERJA STUDIO PERANCANGAN PROGRAM STUDI DESAIN INTERIOR UNIKOM”, Majalah Ilmiah UNIKOM Vol.9, No. 1, Bandung. 